\title{
A conundrum of ethics
}

It is no exaggeration to say that the leaders of biomedical research in the United States are obsessed by the perception that science is rife with fraud, from the mortal sins of data fabrication and plagiarism to the venial sins of arrogance and selfishness. There is a widespread feeling that, if science is to sustain the public trust, scientists must become in real life the paragons of virtue that they are in myth: pure seekers of the truth, generous with their time and data, careful and cautious about what gets into the literature.

A mere handful of protracted but much publicized cases of alleged fraud (including suspicions of an international virus heist and data manipulation so clever that only the Secret Service could detect it) have captured the attention of the public, the U.S. Congress, and the press since the 1980s. Equally important, the belief that the ethical sky is falling has captured the scientific profession itself, which is hell bent on reviving the core values that sustained science in the good old days. It is an honorable and laudable aspiration, but can it be realized?

\section{Values must be taught, but which values?}

There is a consensus that values, once transmitted naturally from mentor to student, must now be explicitly taught. Thus, the National Institutes of Health requires that grant-holding institutions give courses on scientific integrity. And last month, the National Academy of Sciences issued a new version of "On Being a Scientist," a primer of "responsible conduct in science," first published in 1989 (see Reports of note, page 176).

The pity is that the core values of science need to be taught at all. But the reality is that the "right thing" is no longer self-evident now that commerce is thoroughly integrated into university science. A project funded by a federal grant includes the value of open communication. But suppose that same project is also funded by a biotechnology company, which has a legitimate right to privacy of research in progress. Cherished values collide. There may be no uncompromising resolution of the conundrum.

While biomedical scientists struggle with values such as openness, their legal watchdog is trying to turn openness on its head. The much (and justly) maligned Office of Research Integrity
(ORI), known for leaking confidential documents to the detriment of the accused, now wishes to discard any illusion of confidentiality. In the name of openness and to fulfill its self-assigned duty "to correct inaccuracies or misleadling results" in the literature, ORI would routinely release records about cases before they are concluded.

This is a gross distortion of the value of open communication. As Samuel C. Silverstein of Columbia University has correctly noted, the idea that the integrity office has either the jurisdiction or the intelligence to judge the accuracy of research is "preposterous." Silverstein is also president of the Federation of American Societies of Experimental Biology (FASEB), which threatened to take the Office of Research Integrity to court.

Last month, the ORI backed down, perhaps because its track record in court has been a poor one. Its most public and well-deserved defeat came when the Board of Appeals (an administrative law tribunal within the Department of Health and Human Services) ruled in two prominent cases that the ORI had found guilt without first proving there had been a crime. For instance, in the case of Mikulas Popovic, the man who first grew the AIDS virus in large guantities, the appeals board said, "One might anticipate that from all this evidence [presented by ORI], there would at least be a residue of palpable wrongdoing. This is not the case."

Donald Kennedy, in his commentary (page 115) is correct: the accused are better off in the hands of the court. But that is not the way it should be.

The government is rational in its desire to have an organization whose job is to investigate allegations of fraud. But the present system does not work. The Office of Research Integrity should be reconstituted, with a clear mandate to deal with fraud but not the finer points of scientific behaviour, such as lack of collegiality or honest errors in published papers. "On Being a Scientist," raises the right issues and is a useful place to begin. But it avoids answering the hard questions that challenge the old core values of science. Choices have to be made and it is up to the scientific leadership to make them.

Barbara J. Culliton 